\title{
Oleocanthal exerts antitumor effects on human liver and colon cancer cells through ROS generation
}

\author{
ANTONELLA CUSIMANO ${ }^{1}$, DANIELE BALASUS ${ }^{1}$, ANTONINA AZZOLINA ${ }^{1}$, GIUSEPPA AUGELLO ${ }^{1}$, \\ MARIA R. EMMA ${ }^{1}$, CATERINA DI SANO ${ }^{1}$, ROBERTO GRAMIGNOLI ${ }^{2}$, STEPHEN C. STROM $^{2}$, \\ JAMES A. MCCUBREY $^{3}$, GIUSEPPE MONTALTO ${ }^{1,4}$ and MELCHIORRE CERVELLO ${ }^{1}$ \\ ${ }^{1}$ Institute of Biomedicine and Molecular Immunology 'Alberto Monroy', National Research Council \\ (CNR), Palermo, Italy; ${ }^{2}$ Division of Pathology, Department of Laboratory Medicine, Cell Transplantation \\ and Regenerative Medicine, Karolinska Institutet, Stockholm, Sweden; ${ }^{3}$ Department of Microbiology \\ and Immunology, Brody School of Medicine at East Carolina University, Greenville, NC, USA; \\ ${ }^{4}$ Biomedical Department of Internal Medicine and Specialties, University of Palermo, Palermo, Italy
}

Received March 12, 2017; Accepted May 4, 2017

DOI: 10.3892/ijo.2017.4049

\begin{abstract}
The beneficial health properties of the Mediterranean diet are well recognized. The principle source of fat in Mediterranean diet is extra-virgin olive oil (EVOO). Oleocanthal (OC) is a naturally occurring minor phenolic compound isolated from EVOO, which has shown a potent anti-inflammatory activity, by means of its ability to inhibit the cyclooxygenase (COX) enzymes COX-1 and COX-2. A large body of evidence indicates that phenols exhibit anticancer activities. The aim of the present study was to evaluate the potential anticancer effects of OC in hepatocellular carcinoma (HCC) and colorectal carcinoma (CRC) models. A panel of human HCC (HepG2, Huh7, Hep3B and PLC/PRF/5) and CRC (HT29, SW480) cell lines was used. Cells were treated with OC, and cell viability and apoptosis were evaluated. Compared with classical commercially available COX inhibitors (ibuprofen, indomethacin, nimesulide), OC was more effective in inducing cell growth inhibition in HCC and CRC cells. Moreover, OC inhibited colony formation and induced apoptosis, as confirmed by PARP cleavage, activation of caspases $3 / 7$ and chromatin condensation. OC treatment in a dose dependent-manner induced expression of $\gamma \mathrm{H} 2 \mathrm{AX}$, a marker of DNA damage, increased intracellular ROS production and caused mitochondrial depolarization. Moreover, the effects of OC were
\end{abstract}

Correspondence to: Dr Melchiorre Cervello or Dr Antonella Cusimano, Istituto di Biomedicina ed Immunologia Molecolare ‘Alberto Monroy', CNR, Via Ugo La Malfa 153, 90146 Palermo, Italy E-mail: melchiorre.cervello@ibim.cnr.it

E-mail: antonella.cusimano@ibim.cnr.it

Key words: oleocanthal, hepatocellular carcinoma, colorectal carcinoma, reactive oxygen species, apoptosis, extra-virgin olive oil suppressed by the ROS scavenger N-acetyl-L-cysteine. Finally, OC was not toxic in primary normal human hepatocytes. In conclusion, OC treatment was found to exert a potent anticancer activity against HCC and CRC cells. Taken together, our findings provide preclinical support of the chemotherapeutic potential of EVOO against cancer.

\section{Introduction}

In recent years, the health-promoting and disease prevention properties of the Mediterranean diet (MD) have been highlighted (1). The Mediterranean populations, which follow this pattern of eating for cultural and natural reasons, present a reduced incidence of chronic inflammation-derived diseases. The view that the MD is associated with a reduced incidence of inflammatory diseases is supported by a large number of studies (2). Extra-virgin olive oil (EVOO) is a common component of MD, which for some time has been examined in studies that have highlighted its health benefits (3-6). In EVOO a number of phenolic compounds have been identified, including tyrosol (7), hydroxytyrosol (8), oleuropein (9), and many others, as well as Oleocanthal (OC) [(-)-deacetoxyligstroside aglycone]. In 2005, Beauchamp et al identified in OC the pungent component of EVOO that induces a strong prickling sensation in the throat, similar to that caused by the non-steroidal anti-inflammatory drug (NSAID) ibuprofen (10). The authors showed that OC exhibits anti-inflammatory activity, as it is an inhibitor of cyclooxygenases (COXs), COX1 and COX2, two enzymes involved in the synthesis of prostaglandins and thromboxanes from arachidonic acid (10).

Recently, various studies have shown that OC exhibits anticancer activities by inhibiting cell proliferation, migration, and invasion in different human cancer cell types (11-16). In the breast cancer model OC suppresses cell proliferation, invasiveness and tumor growth by inhibiting the HGF-induced phosphorylation of c-Met and suppressing the Brk/paxillin/Racl signaling pathway, via inhibition of Brk phosphorylation (11). In vivo studies in mice have shown that 
OC treatment suppresses tumor cell growth (11). Moreover, further studies have demonstrated that OC inhibits the growth of several breast cancer cell lines by inhibiting the enzymatic activity of mTOR, a serine/threonine kinase which is involved in cell survival and proliferation in cancer cells (17).

Hepatocellular carcinoma (HCC), is an inflammationrelated cancer that arises in the context of hepatic damage and inflammation. HCC is the fifth most common cancer worldwide, characterized by an increasing incidence and a poor prognosis (18-22). It is largely asymptomatic until it is in the advanced state, when the treatments available are often unsuccessful, the standard treatments being surgical resection and liver transplantation. Other treatments, such as chemoembolization and ultrasound ablation techniques also rarely lead to a complete recovery (22). Standard cancer drugs such as doxorubicin, cisplatin, and 5-fluorouracil have a very limited efficacy (22). Moreover, the latest new targeted therapy approved for the treatment of patients with advanced HCC, e.g. sorafenib, has a poor efficacy (23).

In the inflammation process an important role is attributed to the COX enzymes, although the role of the cyclooxygenases in hepatocellular carcinogenesis is still unclear. Some studies have shown an increased expression of COX-2 in patients with different types of liver disease, suggesting its possible role in hepatocarcinogenesis, especially in the early stages (24-26). Results from our laboratory have confirmed the antitumor and pro-apoptotic effects of COX inhibitors used alone or in combination with other targeted specific drugs (27-32). However, our results and those of other authors suggest that often the anticancer activities of COX inhibitors might be due to COX-independent effects (32).

Colorectal cancer (CRC) is one of most common cancers worldwide, with a number of different etiologies. However, the largest proportion of CRC cases has been linked to environmental causes, such as chronic intestinal inflammation (33). Elevated COX-2 expression has been found in most CRC cancer tissues and it is associated with poor prognosis (34-37). Large epidemiological studies have demonstrated that NSAIDs reduce the risk of CRC cancer in humans and, recently, also an antitumoral activity of NSAIDs has been described in CRC (38-40).

Although OC has already been shown to inhibit growth and metastasis as well as tumorigenicity in different tumor cell types, the underlying molecular mechanism of action in HCC and CRC is not yet fully understood.

In this study, we investigated the anticancer effects of OC in HCC and CRC cell lines. Interestingly, OC caused a loss of cell viability and induced apoptosis in both liver and colon cancer cells, without affecting the cell viability of healthy primary hepatocytes, through ROS generation and independently of COX-2 expression.

\section{Materials and methods}

Cell lines, cell culture and reagents. The human hepatocarcinoma cell lines HepG2, Hep3B, Huh7, PLC/PRF/5 and the colon carcinoma cell lines SW480 and HT29 used in this study were maintained in RPMI medium (Sigma-Aldrich, St. Louis, MO, USA), containing 10\% (v/v) Fetal Bovine Serum (FBS) (Gibco, Life Technologies, Monza, Italy).
The HCC cell lines have different characteristics of differentiation, biological behavior, and genetic defects (31). HepG2 and Hep3B cells were obtained from the American Type Culture Collection (ATCC, Rockville, MD, USA). The PLC/PRF/5 cells used in this study were a gift from Professor O. Bussolati (University of Parma, Parma, Italy). The other cell lines used were gifts from various sources: the Huh-7 cells from Professor M. Levrero (Department of Internal Medicine, Sapienza University, Rome, Italy); SW480 cells from Dr J.L. Iovanna (Inserm, Marseille, France); and HT29 cells from Professor S. Travali (University of Catania, Catania, Italy). All cell lines were authenticated by short tandem repeat (STR) profiling (BMR Genomics, Padua, Italy), and used within 6 months of receipt.

OC was synthesized as previously described (41). Nimesulide, SC560 and ibuprofen were purchased from Cayman Chemical (Ann Arbor, MI, USA). All the reagents were dissolved in dimethyl sulfoxide (DMSO; Sigma-Aldrich)

Cell viability assays. Cells ( $5 \times 10^{3} /$ well) were distributed into each well of 96 -well microtiter plates and then incubated overnight. At time 0 , the medium was replaced with fresh complete medium plus $1 \%(\mathrm{v} / \mathrm{v}) \mathrm{FBS}$, and different doses of OC, nimesulide, SC560 and ibuprofen were added. Cells were cultured for 24, 48 and $72 \mathrm{~h}$. At the end of treatment, MTS assays were performed using the CellTiter Aqueous OneSolution kit (Promega Corp., Madison, WI, USA) according to the manufacturer's instructions. Cell viability was expressed as a percentage of the absorbance measured in the control cells. Values were expressed as means \pm SD of three separate experiments, each performed in triplicate. In some experiments, cells were treated with OC plus the antioxidant $\mathrm{N}$-acetyl-L-cysteine (NAC) (Sigma-Aldrich).

Colony formation assays. The effects of different inhibitor concentrations on cell growth were also assessed using a clonogenic assay. For this analysis, $1.0-1.5 \times 10^{3}$ cells were plated in 6-well plates in growth medium, and after overnight attachment cells were exposed either to OC or vehicle for $48 \mathrm{~h}$ in fresh complete medium with $1 \%$ (v/v) FBS. The cells were then washed and allowed to grow for 14 days in drug-free complete medium with $10 \%$ (v/v) FBS, after which the cell colonies were fixed with $70 \%$ ethanol at $4{ }^{\circ} \mathrm{C}$ for $20 \mathrm{~min}$. and stained with crystal violet $\left(0.1 \%\right.$ in $\left.\mathrm{H}_{2} \mathrm{O}\right)$ for $5 \mathrm{~min}$. The plates were rinsed with water, air-dried, photographed and evaluated for colony formation. Colonies containing more than 50 cells were counted.

Data are expressed as a percentage of colonies in untreated cells and are the means \pm SD of three separate experiments, each of which was performed in duplicate.

Caspase activity assays. Cells (5x103/well) were treated with $25 \mu \mathrm{M}$ OC, and after $24 \mathrm{~h}$ the activity of caspases 3 and 7 were measured by the Caspase-Glo ${ }^{\circledR} 3 / 7$ (Promega Corp.) Assay according to the manufacturer's instructions. Results were expressed as arbitrary units (AU). Values were the mean \pm SD of three separate experiments, each performed in duplicate.

Western blot analysis. Cell/well $\left(35 \times 10^{4}\right)$ were plated in 6-well plates. After $24 \mathrm{~h}$ of treatment whole cellular lysates from cells 
A

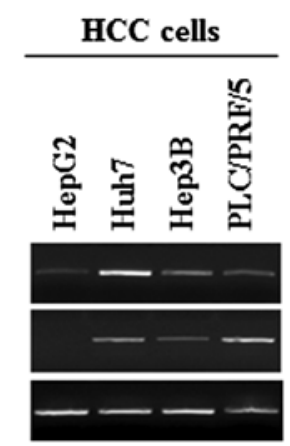

B
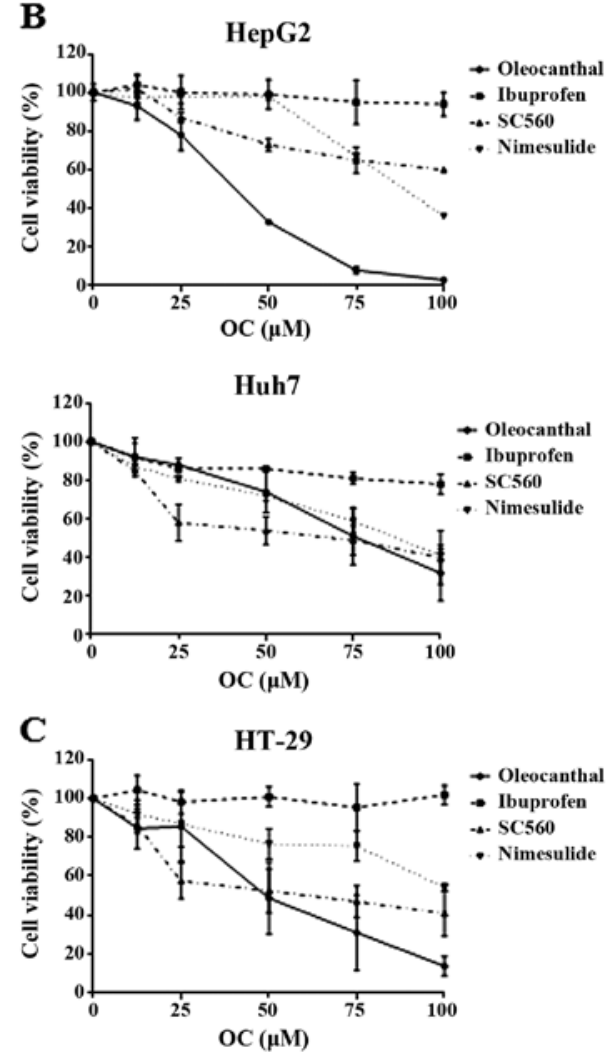

CRC cells
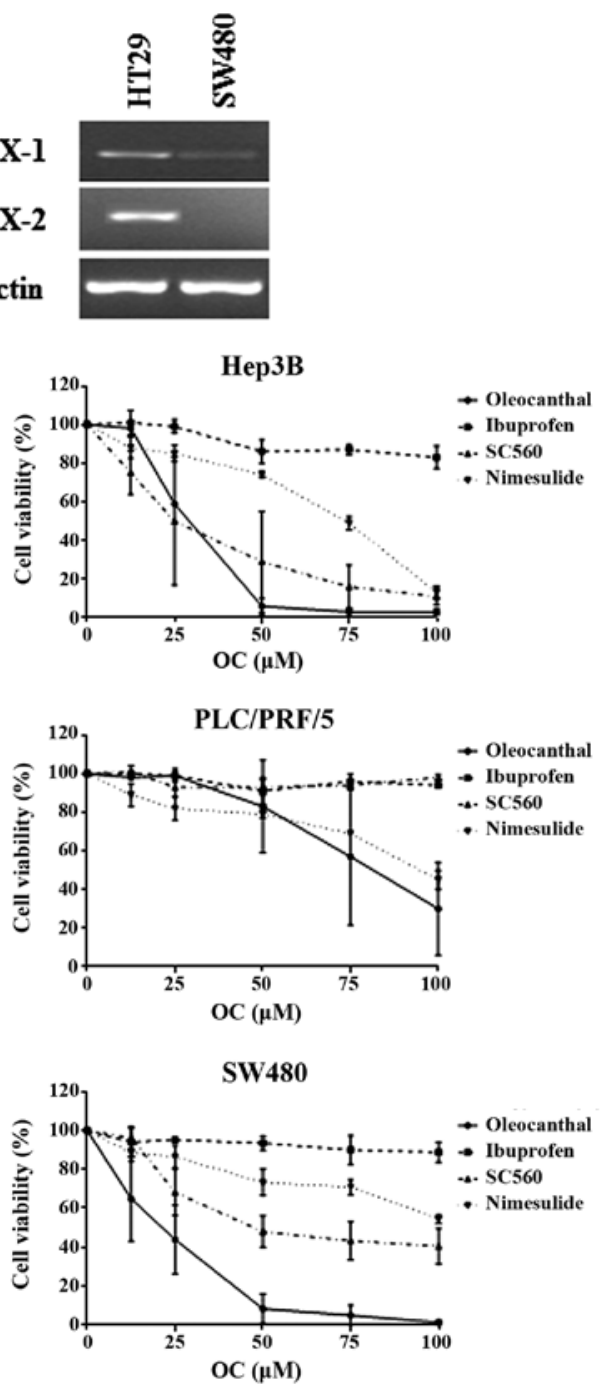

Figure 1. Oleocanthal (OC) treatment inhibits cell viability in HCC and CRC cells. (A) COX-1 and COX-2 mRNA were evaluated by RT-PCR in a panel of HCC and CRC cell lines. (B) HCC and (C) CRC cells were treated with OC, ibuprofen (COX-2 inhibitor), SC560 (COX-1 inhibitor) and nimesulide (dual COX-1 and COX-2 inhibitor) at the indicated concentrations and cell viability was evaluated using MTS assays after $72 \mathrm{~h}$. Data are expressed as a percentage of control cells and are the means \pm SD of three separate experiments, each of which was performed in triplicate.

were obtained using RIPA buffer (Cell Signaling Technologies Inc., Beverly, MA, USA) and western blots were performed using the methodology for the Odyssey ${ }^{\circledR}$ infrared imaging system (LI-COR Biosciences, Lincoln, NE, USA), as previously described (42). Membranes were scanned and analyzed with an Odyssey infrared imaging system (LI-COR Biosciences) using Odyssey 3.0 imaging software. Antibody signals were analyzed as integrated intensities of regions defined around the bands of interest in either channel, with primary antibodies raised against $\beta$-actin (Sigma-Aldrich), phospho-p38, p38, PARP and $\gamma \mathrm{H} 2 \mathrm{AX}$ (Cell Signaling Technologies Inc.).

Flow cytometry analysis. After $24 \mathrm{~h}$ of $\mathrm{OC}$ treatment, $0.5 \times 10^{6}$ cells were collected and stained with FITC-conjugated Annexin $\mathrm{V}$ antibody, and propidium iodide (Apoptosis detection kit; Dojindo, Munich, Germany). The number of viable, apoptotic and necrotic cells were determined using the
FACSCalibur flow cytometer (Becton Dickinson, San Jose, CA, USA). Results are presented as percentage. Values represent the mean \pm SD of two separate experiments.

Measurement of reactive oxygen species (ROS). The intracellular accumulation of ROS was determined using the fluorescent probe $2^{\prime}, 7^{\prime}$-difluorodihydrofluorescein diacetate $\left(\mathrm{H}_{2}\right.$ DCFDA $)$ and MitoSOX ${ }^{\mathrm{TM}}$ Red mitochondrial superoxide indicator (Invitrogen Corp., Camarillo, CA, USA). Cells $\left(2 \times 10^{4}\right)$ were treated with $25-50 \mu \mathrm{M}$ OC for $24 \mathrm{~h}$ and then incubated with the probe in the dark at $37^{\circ} \mathrm{C}$ in $5 \% \mathrm{CO}_{2}$ incubator according to the manufacturer's instructions. Cells were observed with fluorescence microscopy (Axioskop; Zeiss, Oberkochen, Germany) and photographed.

TUNEL assays. Cells were cultured in 8-well chamber slides overnight. After treatment for $24 \mathrm{~h}$ with $25-50 \mu \mathrm{M}$ OC, cells 
A
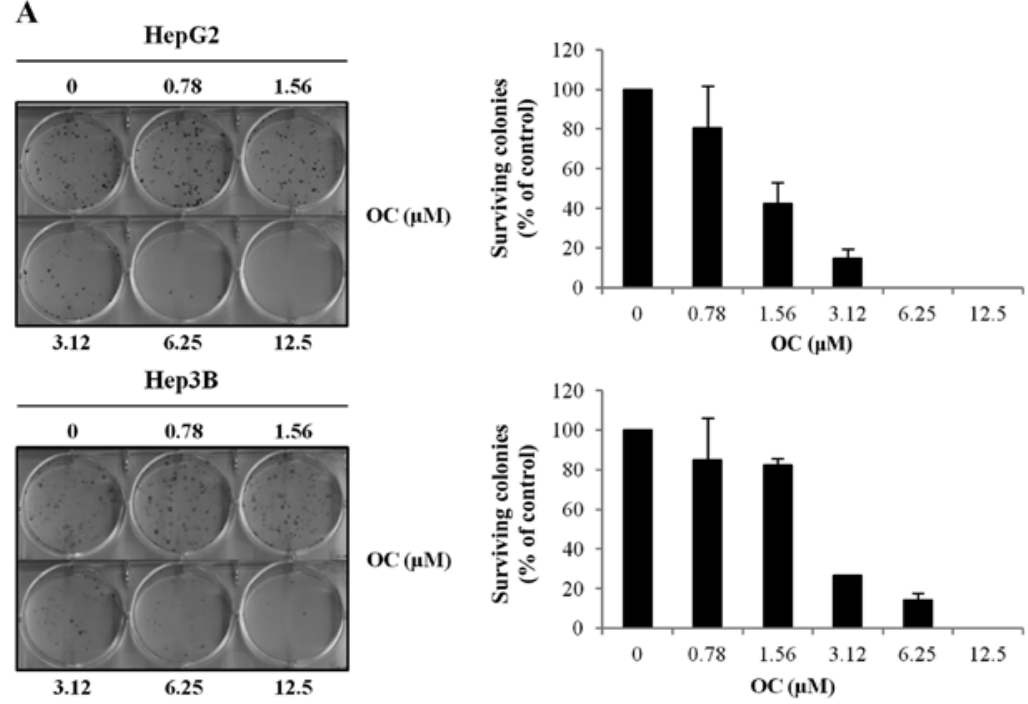

B
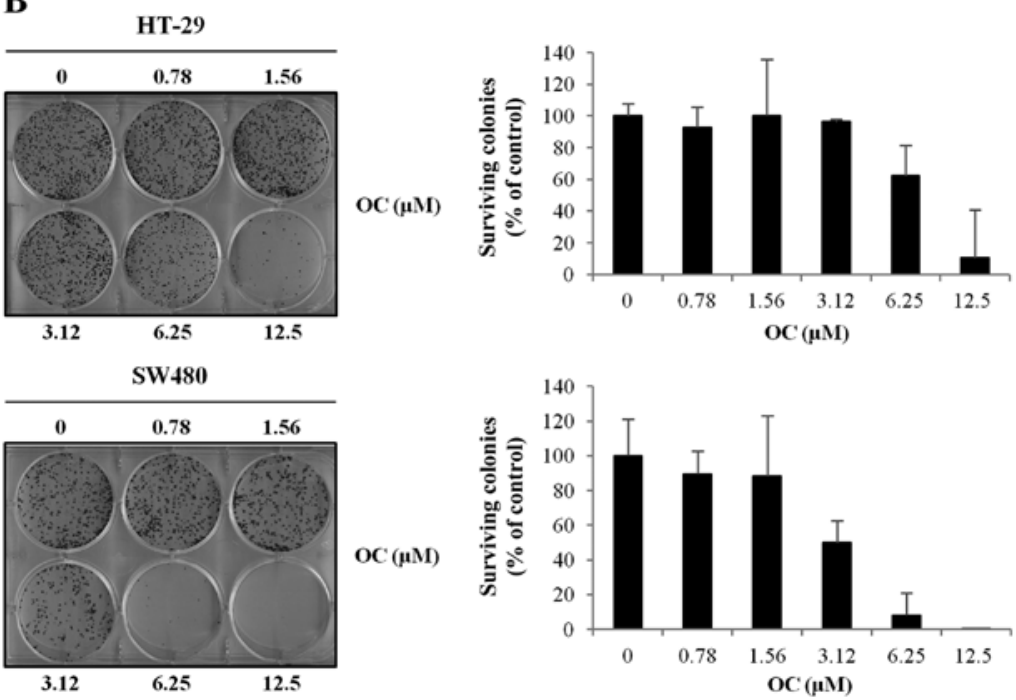

Figure 2. Oleocanthal (OC) treatment inhibits colony formation capacity of HCC and CRC cells. (A) HCC and (B) CRC cells were plated overnight and exposed to OC for $48 \mathrm{~h}$, followed by growth in fresh culture media for 14 days, as described in Materials and methods. Surviving colonies were stained (left panel) and counted (right panel). Data are expressed as a percentage of colonies in untreated cells and are the means of three separate experiments, each of which was performed in duplicate.

were washed twice with PBS and fixed in $4 \%$ paraformaldehyde solution for $25 \mathrm{~min}$ at room temperature. Apoptotic cells were detected by terminal deoxynucleotidyl transferasemediated dUTP nick end-labeling (TUNEL) assay using the DeadEnd $^{\mathrm{TM}}$ Colorimetric TUNEL System kit from Promega Corp., following the manufacturer's instructions. Cells were visualized with an Axioskop microscope (Zeiss).

Measurement of mitochondrial membrane potential. For $\Delta \Psi \mathrm{m}$ measurement, cells $\left(2 \times 10^{4}\right.$ cells/well $)$ in chamber slides were treated with $25-50 \mu \mathrm{M}$ OC for $24 \mathrm{~h}$. JC-1 staining solution $(5 \mu \mathrm{g} / \mathrm{ml}$, Thermo Fisher Scientific Inc., Waltham, MA, USA) was added to both treated and untreated cells at $37^{\circ} \mathrm{C}$ for $15 \mathrm{~min}$, according to the manufacturer's instructions. After washing twice with PBS, mitochondrial membrane potential was monitored by determining the relative amounts of dual emission with a multiple fluorescence reader (Victor; Perkin Elmer, Waltham, MA, USA) and cells were visualized with a fluorescence microscope.
Purification of normal human hepatocytes. All human tissues were collected with informed consent following ethical and institutional guidelines. Liver tissue dissociation and subsequent hepatocyte isolation procedures were performed as previously described (43). Cell viability was assessed by Trypan Blue (Sigma-Aldrich) exclusion method, and plating efficiency assessed as previously described (43).

After 24-48-72 h of exposure to OC, hepatocyte status (ATP content) was assessed using the CellTiter-Glo ${ }^{\circledR}$ Luminescent Cell Viability Assay (Promega Corp.). Fresh medium with drugs was changed daily.

Double-stranded DNA (dsDNA) quantification was performed with a Quant-iT ${ }^{\mathrm{TM}}$ PicoGreen ${ }^{\circledR}$ dsDNA ultrasensitive fluorescent nucleic acid staining kit (Molecular Probes; Invitrogen Corp.), as previously described (44). Briefly, after CellTiter-Glo measurement, each well was incubated with $80 \mu$ l Quant-iT PicoGreen in Tris-Ethylenediaminetetraacetic acid (EDTA) buffer, and the fluorescence intensity was read on a fluorescent spectrometer (Synergy HT; BioTek Instruments, 
A

A HepG2
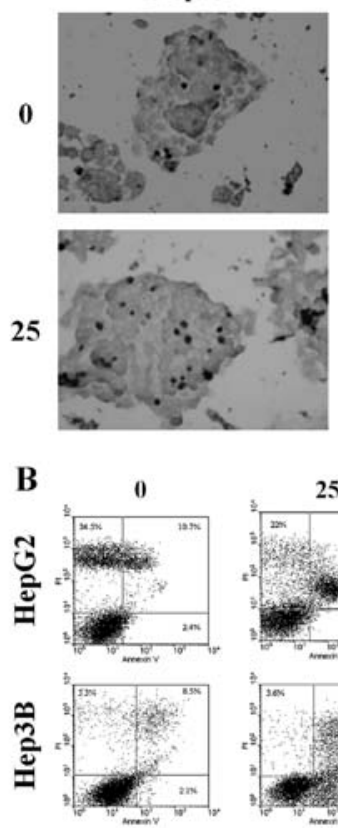

D

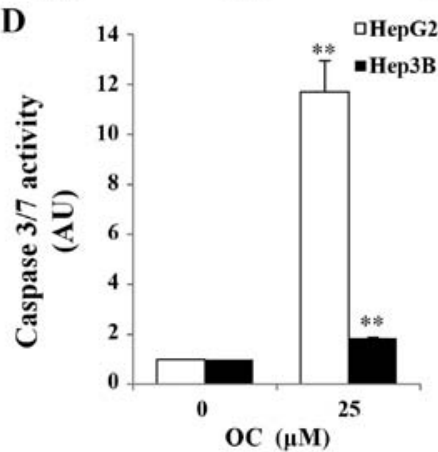

Hep3B
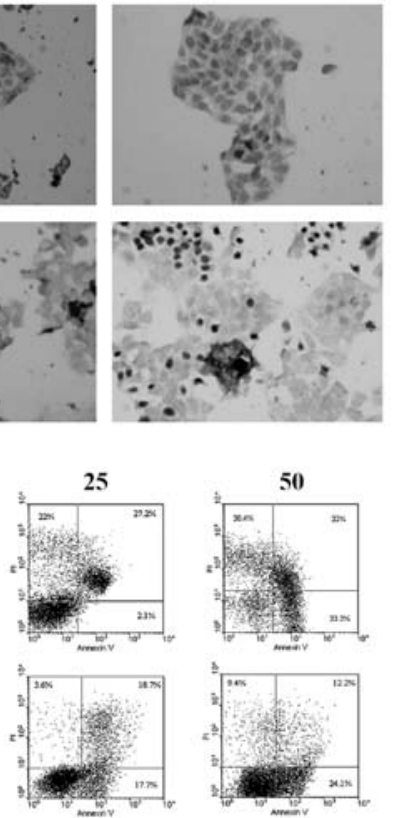

DHepG2

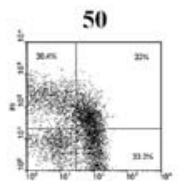

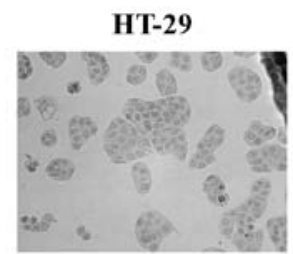
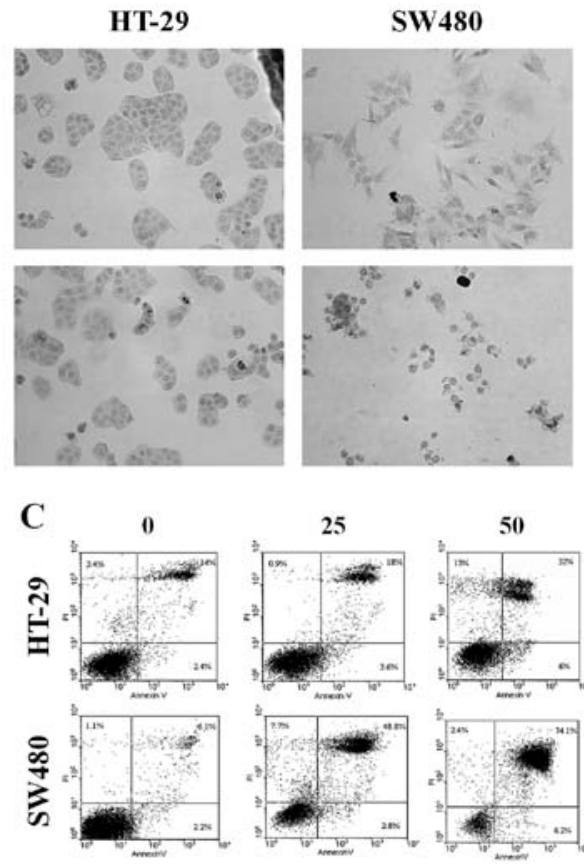

$\mathbf{E}$

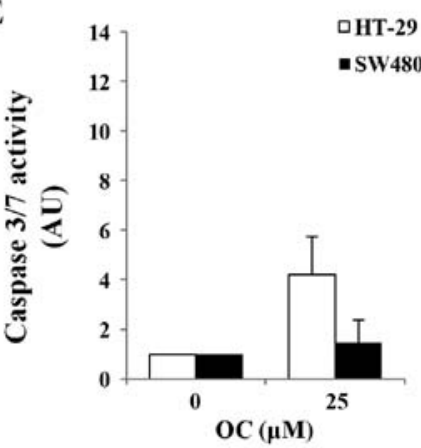

Figure 3. Oleocanthal (OC) treatment induces apoptosis in HCC and CRC cells. (A) Detection of apoptosis by TUNEL assay as described in Materials and methods. Photomicrographs of HepG2, Hep3B, HT29 and SW480 cells treated for $24 \mathrm{~h}$ with $25 \mu \mathrm{M}$ OC. (B and C) Representative dot plot of flow cytometry analysis. Apoptotic cell death was determined by Annexin V/propidium iodide double labeling in HCC and CRC cells. (D) HCC and (E) CRC cells were treated with OC for $24 \mathrm{~h}$, and levels of caspase activity were measured by Caspase-Glo ${ }^{\circledR} 3 / 7$ assays. Data are expressed as arbitrary units (AU) normalized to control value and are the means $\pm \mathrm{SD}$ of three separate experiments, each of which was performed in duplicate. ${ }^{* *} \mathrm{p}<0.01$ versus untreated cells.

Inc., Winooski, VT, USA) at an excitation wavelength of $488 / 15 \mathrm{~nm}$ and an emission wavelength of 528/20 $\mathrm{nm}$. dsDNA concentration was quantified by interpolating the A528 values for the unknowns from a standard curve of $\lambda$ DNA using the equation $(\mathrm{dsDNA}(\mathrm{mg} / \mathrm{ml})=0.1057 \times \mathrm{A} 528-61.322$; $\mathrm{R} 2=0.9941)$. The luminescence produced was normalized to the amount of DNA in each well, and normalized to control cells (0.1\% DMSO). Three separate experiments using different batches of primary isolated human hepatocytes were used, each experiment performed in triplicate.

Statistical analysis. Statistical analysis was performed using Student's two-tailed t-test. Statistical significance was assessed at $\mathrm{p}<0.05$.

\section{Results}

Oleocanthal inhibits cell viability and colony formation capacity of HCC and CRC cells. To investigate the potential anticancer effects of $\mathrm{OC}$ in hepatocellular carcinoma (HCC), we exposed 3 human HCC cell lines, characterized by different properties such as: differentiation status, biological behavior and genetic defects (27). In particular, as regards COX-1 and COX-2 mRNA expression, all cell lines expressed COX-1 mRNA, whereas each type of the cell lines showed different expression levels of COX-2 mRNA (Fig. 1A); PLC/PRF/5 cells expressed the highest COX-2 mRNA levels while in HepG2 cells COX-2 mRNA was undetectable (Fig. 1A).

To determine whether the effects of OC were cell-type specific we also used a different cancer model, i.e. human colorectal carcinoma (CRC). For this purpose, we used the HT29 and SW480 cells, which are known to be COX-2-positive and COX-2-negative, respectively (45) (Fig. 1A).

Since OC displays anti-inflammatory properties similar to the nonsteroidal anti-inflammatory drug (NSAID) ibuprofen (10), a dual inhibitor of cyclooxygenase (COX) enzymes COX-1 and COX-2, we compared the effects on cell viability and cell survival of OC with that of ibuprofen, as well as, the COX-2 inhibitor nimesulide and the COX-1 inhibitor SC560.

Cell viability assays were performed in HCC and CRC cells using different concentrations of $\mathrm{OC}$ and other antiinflammatory compounds (Fig. 1B and C). Of note, after 

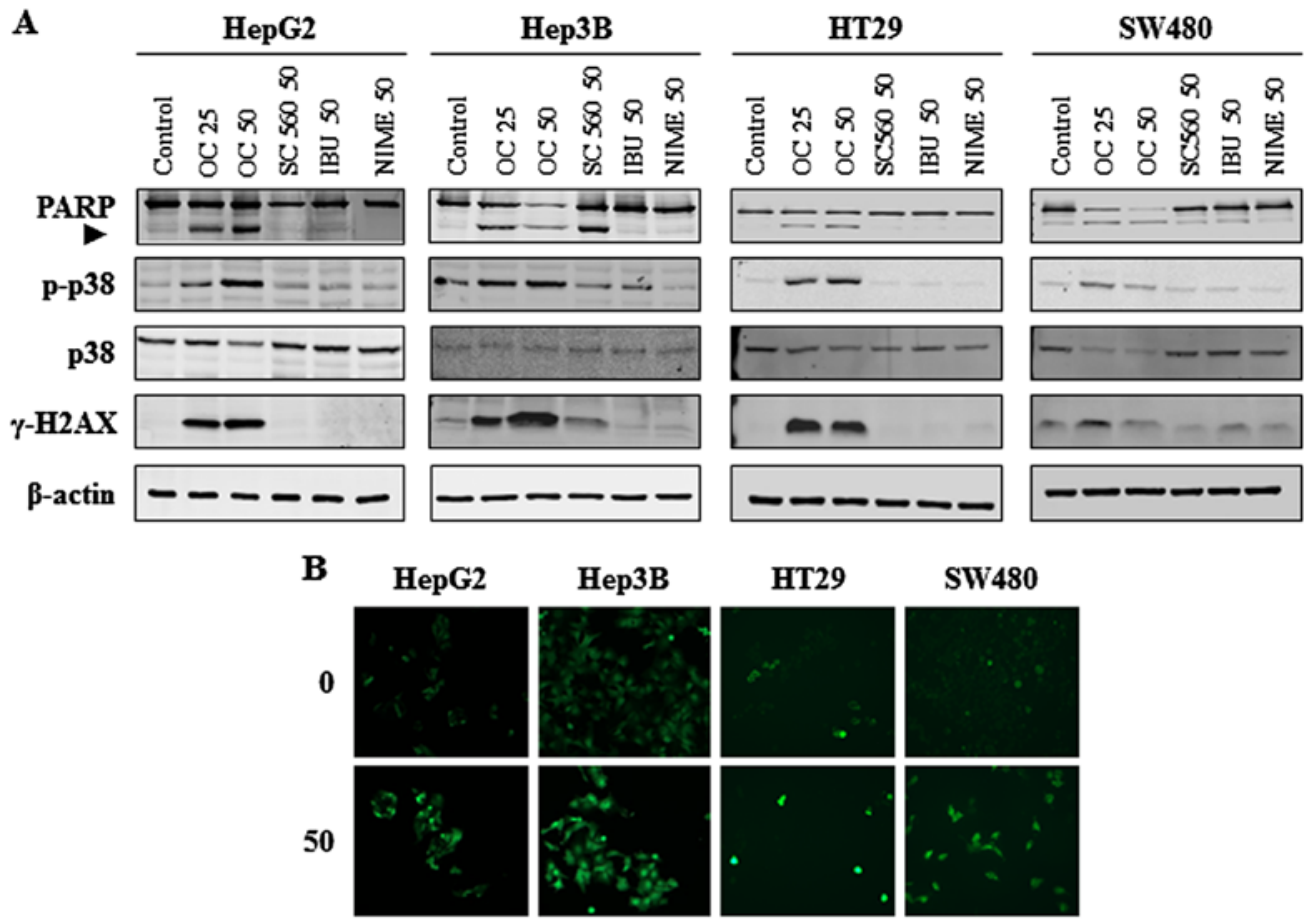

C
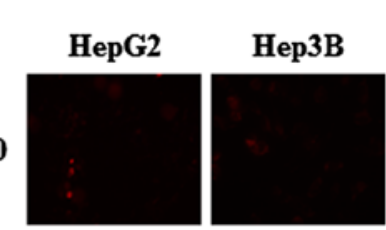

D

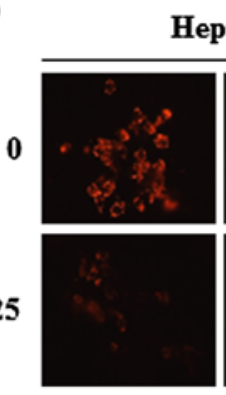

HepG2
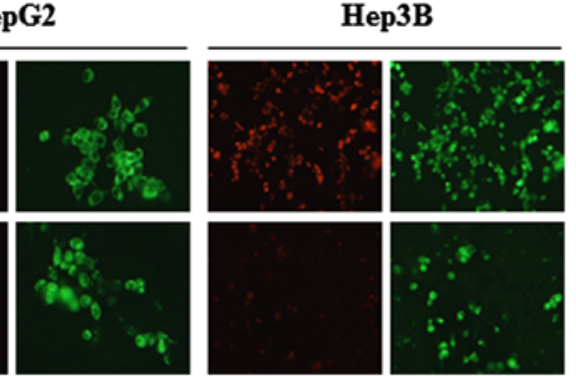

Figure 4. Oleocanthal (OC) treatment induces apoptosis, DNA damage, ROS generation in HCC and CRC cells, and alters mitochondrial membrane potential in HCC cells. (A) Western blot analysis of PARP, phospho-p38 and $\gamma$-H2AX expression in HCC and CRC cells after treatment with OC and NSAIDs at the indicated concentrations $(\mu \mathrm{M})$ for $24 \mathrm{~h}$. The data shown represent three independent experiments with comparable outcomes. The arrowhead indicates the $85 \mathrm{kDa}$ form of PARP. (B) Cells were untreated or treated with OC at the indicated concentrations ( $\mu \mathrm{M})$ for $24 \mathrm{~h}$, and intracellular ROS levels were evaluated by $\mathrm{H}_{2}$ DCFDA staining. The data represent three different experiments with comparable outcomes. (C) Cells were treated with OC at the indicated concentrations $(\mu \mathrm{M})$ for $24 \mathrm{~h}$ and the presence of mitochondrial superoxide anions was evaluated using a MitoSOX-red fluorescent probe. The data represent two different experiments with comparable outcomes. (D) HCC cells were treated with $25 \mu \mathrm{M}$ OC for $24 \mathrm{~h}$ and mitochondrial membrane depolarization was determined by using a MitoProbe JC-1 assay. The JC-1 fluorescence probe exhibits a potential-dependent accumulation in functional mitochondrial membrane where it exhibits a red fluorescence. A decrease in the red/green fluorescence intensity ratio indicates mitochondrial depolarization. Data are representative of two different experiments with comparable outcomes.

treatment for $72 \mathrm{~h}$, OC was more effective than ibuprofen in inhibiting proliferation in all the cell lines analyzed. In Hep3B cells, treatment with $\mathrm{OC}$ showed the strongest inhibition of cell viability with an $\mathrm{IC}_{50}$ value of $26.6 \mu \mathrm{M}$, followed by HepG2 cells $\left(\mathrm{IC}_{50}=41.9 \mu \mathrm{M}\right)$, whereas in Huh7 and PLC/PRF/5 cells, OC displayed an effect comparable to that of nimesulide and SC560 (Fig. 1B).

In addition, as shown in Fig. $1 \mathrm{C}$, OC inhibited cell viability in a dose-dependent manner in both CRC cell lines. OC was more effective than the NSAIDs nimesulide and ibuprofen, and also SC560, as already observed in HCC cells (Fig. 1B). Time course analyses of cell viability assays did not show any time-dependent effects of OC (data not shown).

Several lines of evidence have pointed out that the effect of NSAIDs does not always depend on their effect on the inhibition of COX enzyme activities, i.e. the mechanism of action of NSAIDs is also COX-2-independent $(32,45-47)$. Therefore, we continued all our studies using the HCC cell line HepG2 cells and the CRC SW480 cells, as models for COX-2 negative cells, and Hep3B cells and HT-29, respectively, as models for COX-2 positive cells.

We then investigated the effect of OC on colony formation in HCC and CRC cells. In both cancer types, OC displayed a strong dose-dependent inhibition of colony-forming capacity that was independent of COX-2 expression (Fig. 2A and B).

Oleocanthal induces apoptosis in HCC and CRC cells. To further explore the mechanism of loss of cell viability observed after OC treatment, we analyzed the activation of apoptotic response in $\mathrm{HCC}$ and $\mathrm{CRC}$ cell lines. The results in Fig. 3A show that inhibition of cell viability in HCC and CRC cells after OC treatment is related to the induction of apoptosis as confirmed by the increased number of apoptotic cells (brown/dark nuclei). We also quantified apoptosis after $24 \mathrm{~h}$ of 
A

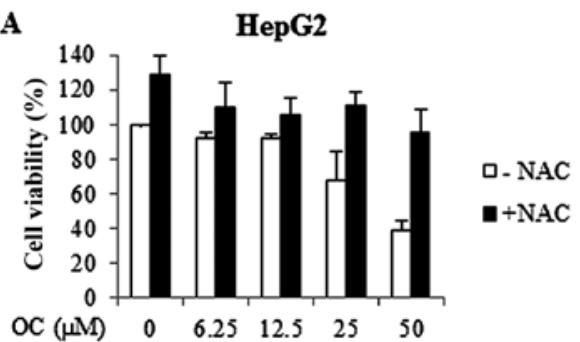

B

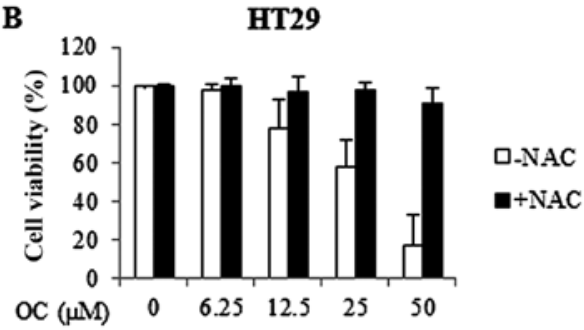

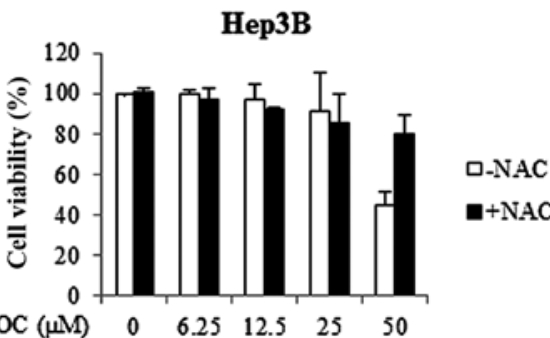

SW480

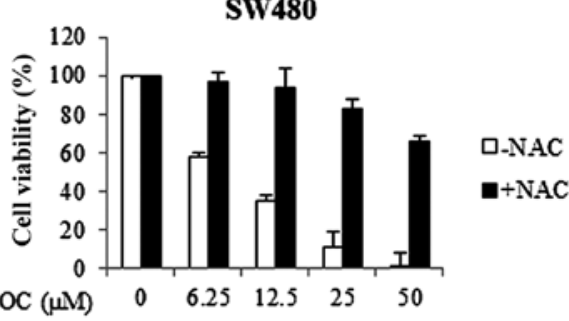

C

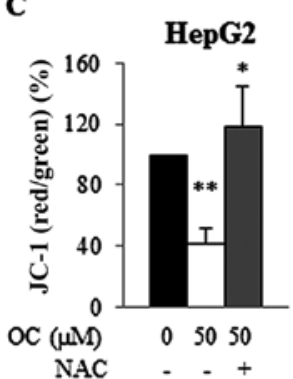

HT29

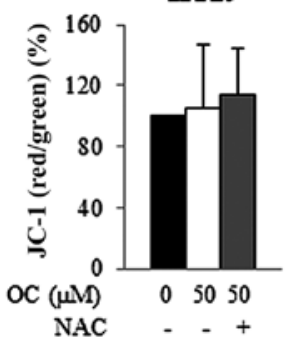

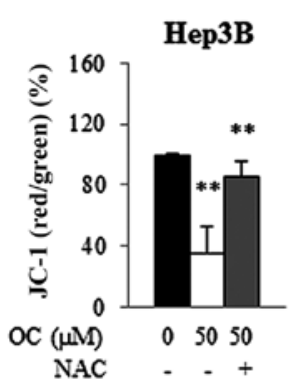

SW480

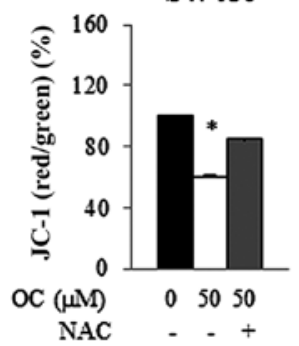

D

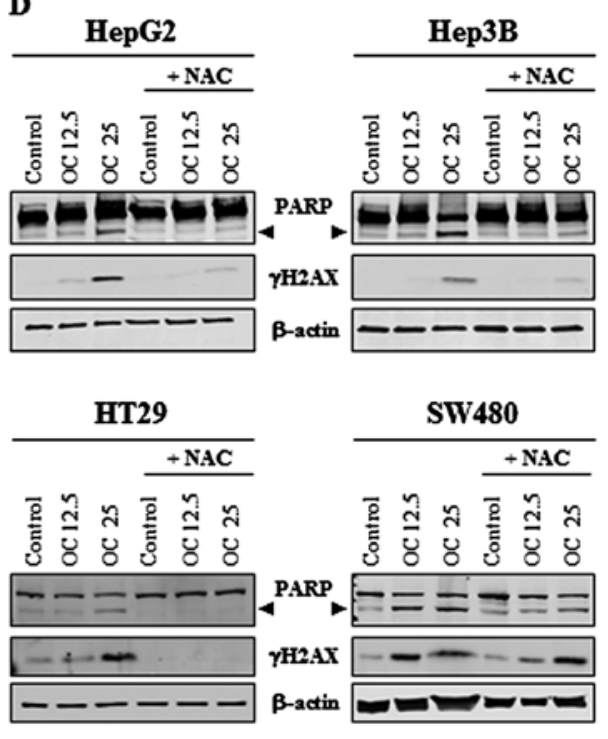

Figure 5. The antioxidant NAC reverses oleocanthal (OC) effects in HCC and CRC cells. (A) HCC and (B) CRC cells were pre-treated (2 h) with NAC $(1 \mathrm{mM})$ before and during OC treatment for $24 \mathrm{~h}$, and cell viability was assessed by MTS. The data are expressed as a percentage of control cells and are the means \pm SD of three separate experiments, each of which was performed in triplicate. (C) Mitochondrial membrane depolarization was determined using a MitoProbe JC-1 assay. Cells were treated with OC with or without $1 \mathrm{mM} \mathrm{NAC}$ for $24 \mathrm{~h}$ and the florescence values measured were reported in a histogram as a percentage of control values. A decrease in the red/green fluorescence intensity ratio indicates mitochondrial depolarization. The data are the means \pm SD of two separate experiments, each of which was performed in duplicate. ${ }^{*} \mathrm{p}<0.05$ and ${ }^{* * *} \mathrm{p}<0.01$ versus untreated cells. (D) Western blot analysis of PARP and $\gamma-\mathrm{H} 2 \mathrm{AX}$ in $\mathrm{HCC}$ and CRC cells treated with the indicated concentrations of OC $(\mu \mathrm{M})$ for $24 \mathrm{~h}$ with or without NAC $(1 \mathrm{mM})$. Data shown are representative of independent experiments with comparable outcomes. The arrowhead indicates the $85 \mathrm{kDa}$ form of PARP.

treatment with $\mathrm{OC}$ by flow cytometry analysis after staining cells with Annexin V/PI (Fig. 3B and C). The percentage of apoptotic cells increased after OC treatment from $10 \%$ in untreated Hep3B cells to 30\% in Hep3B cells treated with $50 \mu \mathrm{M} \mathrm{OC}$, and from 10 to $56 \%$ in HepG2 cells (Fig. 3B).

In CRC cells, the percentage of apoptotic cells increased from $14 \%$ to $29 \%$ in HT29 and from 17 to $65 \%$ in SW480 after treatment with $50 \mu \mathrm{M}$ OC (Fig. 3C). All experiments were performed in $1 \%$ FCS, a growth condition that could explain the presence of some dead cells among the untreated cells (control).

Apoptosis induction was also investigated by analyzing caspase activation. The caspase assay displayed an activation of caspases $3 / 7$ after $24 \mathrm{~h}$ of treatment with $25 \mu \mathrm{M}$ OC
(Fig. 3D and E) in all cell lines. In addition, western blot analyses of HCC and CRC cell lysates showed cleavage of Poly (ADP-ribose) polymerase (PARP) after treatment with OC in HepG2, HT29 and SW480 cells, and also after treatment with OC and SC560 in Hep3B cells. In contrast, a dose of either $50 \mu \mathrm{M}$ ibuprofen or nimesulide did not induce the cleavage of PARP in any of the cell lines (Fig. 4A). Western blot analyses after OC treatment also indicated an increase in phosphorylated levels of the stress kinase p38, known to be involved in death signaling (Fig. 4A). Taken together these data confirm that OC induced apoptosis in HCC and CRC cells.

Oleocanthal increases reactive oxygen species (ROS) generation in HCC and CRC cells. A number of studies have 

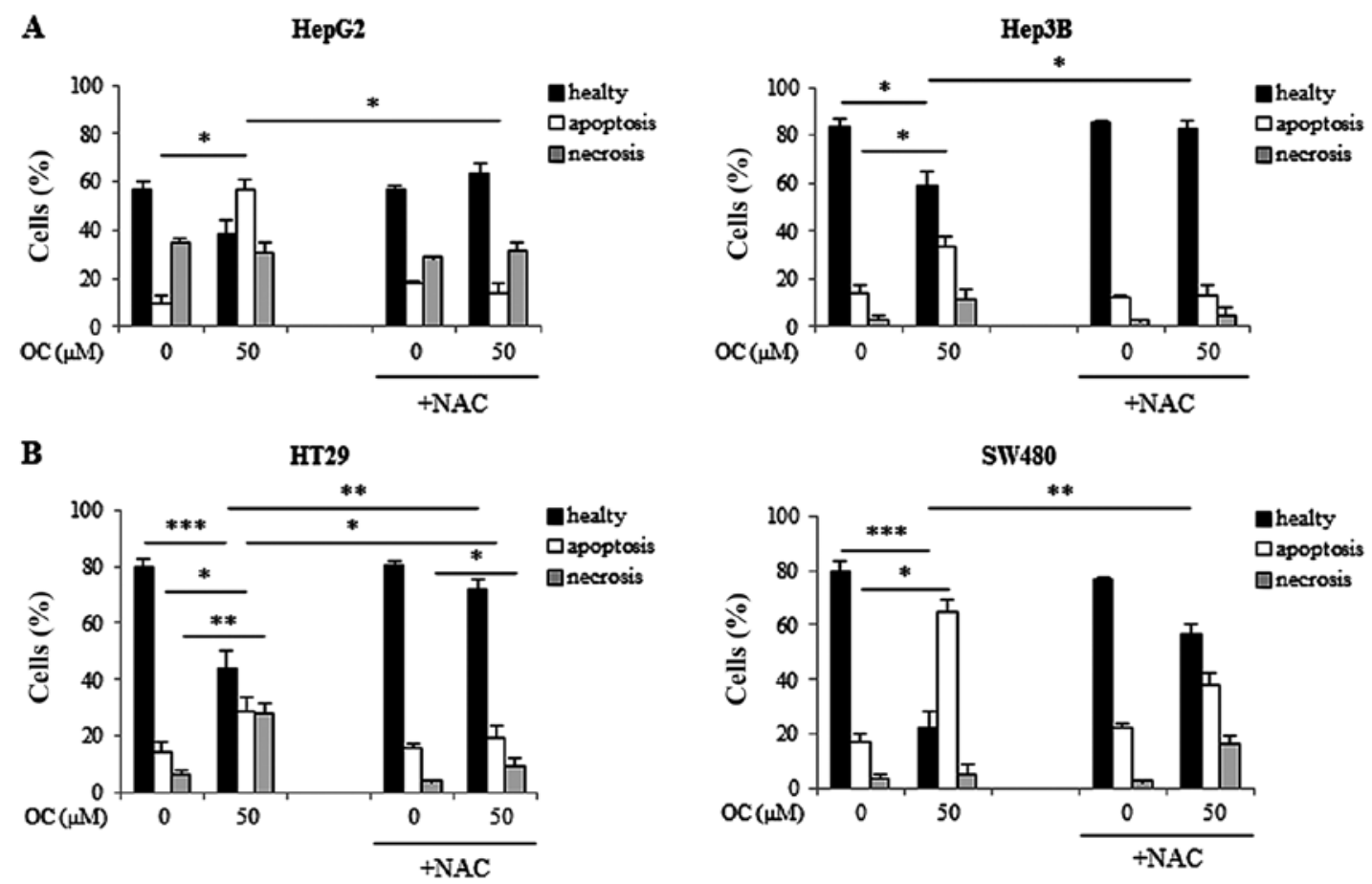

Figure 6. The antioxidant NAC rescues cell viability after oleocanthal (OC) treatment. (A) HCC and (B) CRC cells were pre-treated (2 h) with NAC (1 mM) before and during $\mathrm{OC}$ treatment for $24 \mathrm{~h}$. Flow cytometry analysis was performed using Annexin V/propidium iodide double staining as indicated in Materials and methods. Percentage values of healthy, apoptotic and necrotic cells are reported in histograms. Data are the means \pm SD of three separate experiments performed in duplicate. ${ }^{*} \mathrm{p}<0.05,{ }^{* *} \mathrm{p}<0.01,{ }^{* * *} \mathrm{p}<0.001$ versus untreated cells.

shown that phenolic compounds may have pro-oxidant activities via the production of reactive oxygen species (ROS), and that ROS generation in cells is an effective apoptotic inducer (48-50).

To better understand the mechanism of apoptosis induced by $\mathrm{OC}$, we evaluated ROS production, using the cell-permeable fluorescent probe $\mathrm{H}_{2}$ DCFDA. OC treatment induced intracellular ROS production in both HCC and CRC cells (Fig. 4B). Moreover, to identify the type of ROS produced on OC treatment, we evaluated the presence of superoxide anions with the MitoSOX-red fluorescent probe. As shown in Fig. 4C, the production of superoxide anions increased after treatment with OC in HCC cell lines.

Since high levels of ROS are known to produce DNA damage and impair mitochondrial integrity, we next evaluated the effect of OC treatment on phospho-H2AX $(\gamma-\mathrm{H} 2 \mathrm{AX})$ expression levels and on mitochondrial membrane potential. Western blot analysis showed a strong increase in $\gamma$-H2AX histone levels on OC treatment in all cell lines (Fig. 4A). These results indicate a strong induction of ROS production which caused DNA damage after treatment with OC.

$\Delta \psi \mathrm{m}$ were assessed by staining OC-treated HCC cells with the membrane permeable dye JC-1, a widely-used probe for determining changes of $\Delta \psi \mathrm{m}$ (Fig. 4D). JC-1 specifically shows potential-dependent accumulation in depolarized mitochondria, displaying a red to green fluorescence shift. The intensity of JC-1 red fluorescence was lower in the OC-treated cells than in the control, indicating a depolarization of the mitochondrial membrane (Fig. 4D).

Treatment with $N$-acetyl-L-cysteine (NAC) reverses the cytotoxic effects of oleocanthal in HCC and CRC cells. In the previous experiments, we observed an induction of ROS generation due to treatment with OC in HCC and CRC cells. To determine whether OC induces cytotoxic effects via ROS generation, we tested the effects of the ROS scavenger $\mathrm{N}$-acetyl-L-cysteine (NAC) on cell viability, on apoptosis activation and on DNA damage. For these purposes, cells were pre-treated with NAC ( $1 \mathrm{mM})$ for $2 \mathrm{~h}$ and subsequently treated with different concentrations of $\mathrm{OC}$ for an additional $24 \mathrm{~h}$ in the presence of NAC.

The cell morphology of HCC and CRC cell lines after $24 \mathrm{~h}$ of OC treatment was examined by light microscopy with or without the presence of NAC (not shown). In samples treated with both OC and NAC there was a reduction in the number of floating cells, cells remained spread as non-treated cells, suggesting a recovery of cell vitality, otherwise in samples treated with OC alone cells were shrunken, detached, and fragmented into membrane-bound apoptotic bodies. The recovery in cell viability was confirmed by MTS assays. In all cell lines, NAC significantly decreased the OC-induced inhibition of cell viability (Fig. 5A and $\mathrm{B}$ ). In addition, treatment with NAC abrogated OC-induced mitochondrial membrane depolarization and the ratio of red/green JC-1 fluorescence was restored to normal levels (Fig. 5C).

Furthermore, as shown by western blot analysis (Fig. 5D), treatment with NAC also prevented OC-induced PARP cleavage and $\gamma$-H2AX activation.

Finally, apoptosis inhibition by NAC treatment was also confirmed by flow cytometry analysis. Flow cytometry analysis of cells treated with $50 \mu \mathrm{M}$ OC in the presence or absence of NAC confirmed that NAC prevented OC-induced apoptosis, leading to the recovery of viable cells (Fig. 6A and B). In Hep3B cells, the percentage of apoptotic cells declined from 
$\mathbf{A}$

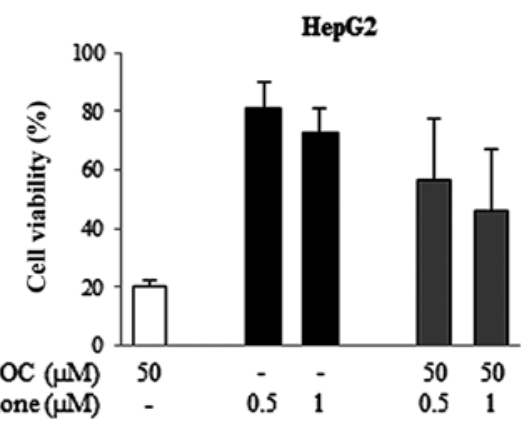

B

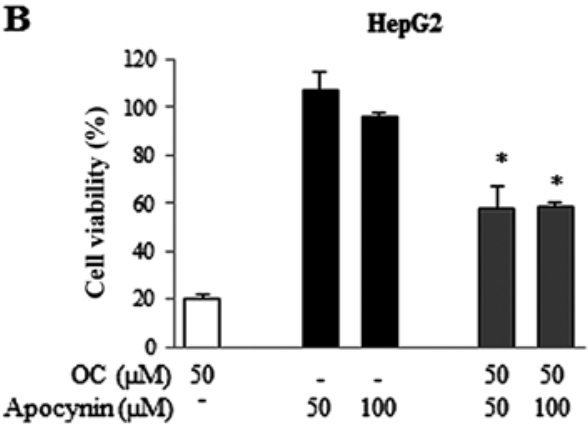

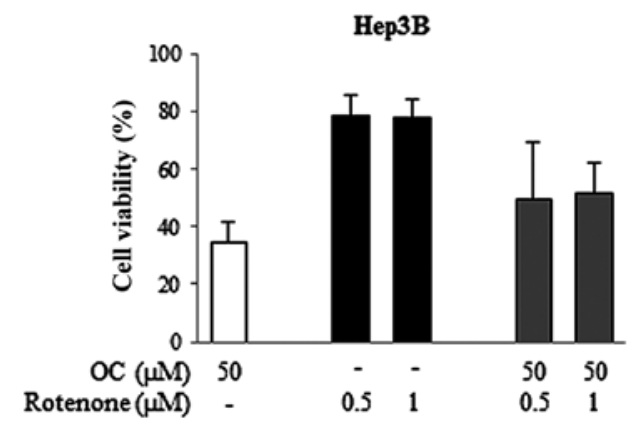

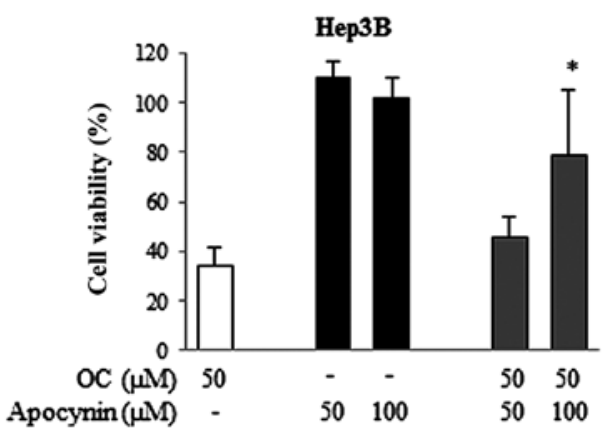

Figure 7. NADPH oxidase enzyme is the main source of ROS in HCC cells. (A) Cells were co-treated with oleocanthal (OC) and MRC complex I inhibitor rotenone at the indicated concentrations for $24 \mathrm{~h}$ and cell viability was evaluated using MTS assays. Data are expressed as a percentage of control cells and are the means \pm SD of three separate experiments, each of which was performed in triplicate. (B) Cells were co-treated with OC and NADPH oxidase inhibitor apocynin at the indicated concentrations for $24 \mathrm{~h}$ and cell viability was evaluated using MTS assays. Data are expressed as a percentage of control cells and are the means \pm SD of three separate experiments, each of which was performed in triplicate. ${ }^{*}$ p $<0.05$ versus cells treated with OC.

$33 \pm 8 \%$ after treatment with $\mathrm{OC}$ to $13 \pm 1 \%$ after treatment with OC plus NAC. In HepG2 cells the percentage of apoptotic cells decreased from $56 \pm 6 \%$ after treatment with OC to $13 \pm 9 \%$ after treatment with OC plus NAC (Fig. 6A). In SW480 cells, the percentage of apoptotic cells diminished from $65 \pm 18 \%$ after treatment with $\mathrm{OC}$ to $38 \pm 2 \%$ after treatment with OC plus NAC. In HT29 cells, the percentage of apoptotic cells declined from $29 \pm 4 \%$ after treatment with OC to $19 \pm 4 \%$ after treatment with OC plus NAC (Fig. 6B).

Taken together, these results indicated that the oxidative stress induced by OC treatment reduced the cell viability of HCC and CRC cells, and that apoptosis activation, mitochondrial and DNA damage are downstream of the oxidative stress.

NADPH oxidase enzyme is the main source of ROS in HCC cells treated with $O C$. We then investigated the source(s) of ROS in cells treated with OC. The major recognized sources of ROS in cells are the mitochondrial respiratory chain (MRC) complexes (51) and the NADPH oxidase (NOX) enzyme $(52,53)$. We analyzed the effects of specific inhibitors of each component of MRC and of NADPH oxidase in cells treated with OC. The MRC complex I inhibitor rotenone, complex II inhibitor thenoyltrifluoroacetone (TTFA), complex III inhibitor antimycin, complex IV inhibitor sodium azide and complex $\mathrm{V}$ inhibitor oligomycin were used. HCC cells were treated with $\mathrm{OC}$ alone or in combination with each single MRC inhibitor at different concentrations for $24 \mathrm{~h}$, after which cell viability assays were performed. All of them failed to revert cell growth inhibition induced by OC (data not shown), with the exception of rotenone, which reversed the effect of $\mathrm{OC}$, however, the inhibition did not reach statistical significance (Fig. 7A).

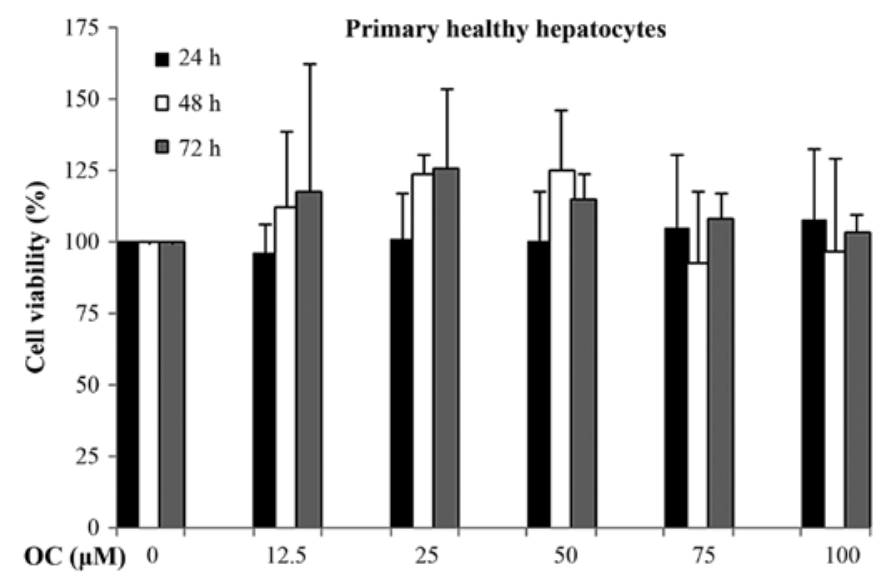

Figure 8. Oleocanthal (OC) is not cytotoxic for primary human hepatocytes. Primary human hepatocytes were treated with $\mathrm{OC}$ at the indicated concentrations and cell viability was evaluated using the CellTiter-Glo ${ }^{\circledR}$ assay after 24, 48 and $72 \mathrm{~h}$. Data are expressed as a percentage of control cells and are the means \pm SD of three separate experiments, each of which was performed in triplicate.

Next, the effects of apocynin, an inhibitor of NADPH oxidase, were examined. The results shown in Fig. 7B demonstrate that in HCC cell lines apocynin significantly prevented OC-induced cell growth inhibition. In Hep3B cells cultured in the presence of apocynin, cell viability increased from $36 \%$ to $78.8 \%$ in samples treated with OC, whereas in HepG2 cells it increased from 20 to $58 \%$.

These results suggest that both MRC complex I and NADPH oxidase are the main sources of ROS in HCC cells treated with OC. 
$O C$ is not cytotoxic in primary normal human hepatocytes. Finally, we tested the effects of OC on primary normal human hepatocytes, measuring the levels of cytotoxicity by cell viability assays. Surprisingly, prolonged treatment with OC (72 h) did not result in reduced hepatocyte viability (Fig. 8). The percentage of hepatocyte viability was unaffected even at higher OC doses (100 $\mu \mathrm{M})$. These results suggest that $\mathrm{OC}$, a natural compound, is cytotoxic for cancer cells but does not have any effect on the cell viability of normal healthy hepatocytes.

\section{Discussion}

Oleocanthal (OC) was first described as anti-inflammatory ibuprofen-like compound (10). We and other research groups have demonstrated that ibuprofen and other NSAID molecules can act as anticancer drugs $(27,28,45-47)$. In the current study, we compared the effects on cell viability of OC in comparison to other NSAIDs, such as the COX-1 inhibitor SC560, the dual COX-1/COX-2 inhibitor ibuprofen and the COX-2 inhibitor nimesulide. Moreover, to better investigate the role of COX-2 we used HCC and CRC cell lines which expressed different levels of COX-2, i.e. Hep3B and HT29 as COX-2 positive cells, and HepG2 and SW480 as COX-2 negative cells. We demonstrated that $\mathrm{OC}$ exerted antitumor activities in $\mathrm{HCC}$ and CRC cells. Our results demonstrated that the OC inhibitory effect on cell viability was more effective than the effects of NSAIDs in all the cell lines tested, and, moreover, its effects were COX-2-independent. Interestingly at the same dose, OC had no effect on normal human hepatocytes, suggesting that it inhibits cancer cell viability while sparing normal cells.

OC inhibited the capacity of HCC and CRC cells to form colonies and induced apoptosis as demonstrated by the induction of PARP cleavage as well as the activation of caspases 3/7. Moreover, OC treatment induced intracellular ROS production in HCC and CRC cells. In particular, in HCC cells we observed a specific induction in superoxide anions.

It is well known that high levels of ROS cause damage in all cellular compartments. For example, they can impair mitochondrial integrity. The $\gamma-\mathrm{H} 2 \mathrm{AX}$ histone is a well-known and established marker of DNA damage, recruited in DNA double strand break (DSBs) foci to allow the assembling of repair machinery. Mitochondrial membrane potential $(\Delta \psi \mathrm{m})$ represents an important parameter of mitochondrial function and integrity. After OC treatment, the stability of mitochondrial membrane potential was significantly impaired in all cell lines.

ROS also causes DNA damage, and we observed a strong induction of $\gamma$-H2AX levels, a marker of DNA damage, in all cell lines treated with OC. Consequently, the ROS scavenger NAC rescued cell viability, reduced the number of apoptotic cells and prevented PARP cleavage after OC treatment in all cell lines. Furthermore, the increase in $\gamma$-H2AX expression, observed after treatment with $\mathrm{OC}$, was reversed by treatment with NAC, and mitochondrial function was also restored after co-treatment with NAC.

We identified NADPH oxidase as a main source of ROS induced by $\mathrm{OC}$ treatment, as demonstrated by the improvement in cell viability of cells co-treated with OC and the NADPH oxidase inhibitor apocynin. However, our results suggest that also the MRC complex I might be a source of
ROS, particularly in the form of superoxide anions. In fact, cells co-treated with OC and the MRC complex I inhibitor rotenone showed a tendency to recover cell viability in HepG2 and in Hep3B cells.

Polyphenols were first indicated as antioxidant components of the diet (54) and initial evidence supported a role of polyphenols in the prevention of cardiovascular and neurodegenerative disorders, cancers and other diseases due to their antioxidant activities. Despite this, the results of the present study demonstrate that oleocanthal, a phenolic compound of EVOO, exerts a pro-oxidant action on HCC and CRC cells. In agreement with this finding, numerous studies in recent years have suggested that polyphenols might also exhibit pro-oxidant effects by generating ROS $(49,50,55)$. Therefore, ROS could be said to have a Janus face nature, as it might contribute on the one hand to carcinogenesis, but, on the other, might induce cancer cell growth arrest, apoptosis, or necrosis (56). The precise mechanism(s) of this behavior is, however, as yet unclear. It has been speculated that malignant cells, living under an increased level of oxidative stress, could be more vulnerable to further ROS increases (57). Studies indicate that normal cells show a lower steady-state level of ROS than cancer cells and a constant level of reducing equivalents (58). The different redox status of normal and cancer cells would allow the development of new promising therapeutic strategies based on drugs that might alter redox equilibrium.

In our present study, OC proved to be an excellent anticancer drug for its ability to kill cancer cells without affecting normal cells. Overall, our results highlight the potential of $\mathrm{OC}$ in the treatment of $\mathrm{HCC}$ and $\mathrm{CRC}$, and provide a basis for future investigation into its use in humans.

\section{Acknowledgements}

This work was supported by PON DI.ME.SA. (Programma Operativo Nazionale Ricerca e Competitività 2007/2013 Progetto 'DI.ME.SA'. PON02_00451_3361785. Valorisation of typical products of the Mediterranean diet and their nutraceutical use to improve health) granted to G.M. and M.C. Authors thank Dr Amos B. Smith III and Dr Gary Beauchamp, The Monell Chemical Senses Center, Philadelphia, PA, USA, for a generous sample of OC.

\section{References}

1. Colomer R and Menéndez JA: Mediterranean diet, olive oil and cancer. Clin Transl Oncol 8: 15-21, 2006.

2. Tripoli E, Giammanco M, Tabacchi G, Di Majo D, Giammanco S and La Guardia M: The phenolic compounds of olive oil: Structure, biological activity and beneficial effects on human health. Nutr Res Rev 18: 98-112, 2005.

3. Cicerale S, Lucas LJ and Keast RS: Antimicrobial, antioxidant and anti-inflammatory phenolic activities in extra virgin olive oil. Curr Opin Biotechnol 23: 129-135, 2012.

4. Cicerale S, Conlan XA, Sinclair AJ and Keast RS: Chemistry and health of olive oil phenolics. Crit Rev Food Sci Nutr 49: 218-236, 2009.

5. Cicerale S, Lucas L and Keast R: Biological activities of phenolic compounds present in virgin olive oil. Int J Mol Sci 11: 458-479, 2010.

6. Caramia G, Gori A, Valli E and Cerretani L: Virgin olive oil in preventive medicine: From legend to epigenetics. Eur J Lipid Sci Technol 114: 375-388, 2012.

7. Rafehi H, Ververis K and Karagiannis TC: Mechanisms of action of phenolic compounds in olive. J Diet (Suppl) 9: 96-109, 2012. 
8. Visioli $\mathrm{F}$ and Bernardini E: Extra virgin olive oil's polyphenols: Biological activities. Curr Pharm Des 17: 786-804, 2011.

9. Omar SH: Oleuropein in olive and its pharmacological effects. Sci Pharm 78: 133-154, 2010.

10. Beauchamp GK, Keast RSJ, Morel D, Lin J, Pika J, Han Q, Lee C-H, Smith AB and Breslin PAS: Phytochemistry: Ibuprofen-like activity in extra-virgin olive oil. Nature 437: 45-46, 2005.

11. Akl MR, Ayoub NM, Mohyeldin MM, Busnena BA, Foudah AI, Liu Y-Y and Sayed KA: Olive phenolics as c-Met inhibitors: (-)-Oleocanthal attenuates cell proliferation, invasiveness, and tumor growth in breast cancer models. PLoS One 9: e97622, 2014.

12. Elnagar AY, Sylvester PW and El Sayed KA: (-)-Oleocanthal as a c-Met inhibitor for the control of metastatic breast and prostate cancers. Planta Med 77: 1013-1019, 2011.

13. Scotece M, Gómez R, Conde J, Lopez V, Gómez-Reino JJ, Lago F, Smith AB III and Gualillo O: Oleocanthal inhibits proliferation and MIP-1 $\alpha$ expression in human multiple myeloma cells. Curr Med Chem 20: 2467-2475, 2013.

14. Fogli S, Arena C, Carpi S, Polini B, Bertini S, Digiacomo M, Gado F, Saba A, Saccomanni G, Breschi MC, et al: Cytotoxic activity of oleocanthal isolated from virgin olive oil on human melanoma cells. Nutr Cancer 68: 873-877, 2016

15. Pei T, Meng Q, Han J, Sun H, Li L, Song R, Sun B, Pan S, Liang D and Liu L: (-)-Oleocanthal inhibits growth and metastasis by blocking activation of STAT3 in human hepatocellular carcinoma. Oncotarget 7: 43475-43491, 2016.

16. Khanal P, Oh W-K, Yun HJ, Namgoong GM, Ahn S-G Kwon S-M, Choi H-K and Choi HS: p-HPEA-EDA, a phenolic compound of virgin olive oil, activates AMP-activated protein kinase to inhibit carcinogenesis. Carcinogenesis 32: 545-553, 2011.

17. Khanfar MA, Bardaweel SK, Akl MR and El Sayed KA: Olive oil-derived oleocanthal as potent inhibitor of mammalian target of rapamycin: Biological evaluation and molecular modeling studies. Phytother Res 29: 1776-1782, 2015.

18. Dhanasekaran R, Limaye A and Cabrera R: Hepatocellular carcinoma: Current trends in worldwide epidemiology, risk factors, diagnosis, and therapeutics. Hepat Med 4: 19-37, 2012.

19. El-Serag HB: Epidemiology of viral hepatitis and hepatocellular carcinoma. Gastroenterology 142: 1264-1273.e1, 2012.

20. Ferlay J, Shin H-R, Bray F, Forman D, Mathers C and Parkin DM: Estimates of worldwide burden of cancer in 2008: GLOBOCAN 2008. Int J Cancer 127: 2893-2917, 2010.

21. Schütte K, Bornschein J and Malfertheiner P: Hepatocellular carcinoma - epidemiological trends and risk factors. Dig Dis 27: $80-92,2009$

22. Thomas MB and Zhu AX: Hepatocellular carcinoma: The need for progress. J Clin Oncol 23: 2892-2899, 2005.

23. Llovet JM, Ricci S, Mazzaferro V, Hilgard P, Gane E, Blanc J-F, de Oliveira AC, Santoro A, Raoul J-L, Forner A, et al; SHARP Investigators Study Group: Sorafenib in advanced hepatocellular carcinoma. N Engl J Med 359: 378-390, 2008.

24. Cervello M and Montalto G: Cyclooxygenases in hepatocellular carcinoma. World J Gastroenterol 12: 5113-5121, 2006.

25. Koga H, Sakisaka S, Ohishi M, Kawaguchi T, Taniguchi E, Sasatomi K, Harada M, Kusaba T, Tanaka M, Kimura R, et al: Expression of cyclooxygenase-2 in human hepatocellular carcinoma: Relevance to tumor dedifferentiation. Hepatology 29: 688-696, 1999.

26. Leng J, Han C, Demetris AJ, Michalopoulos GK and Wu T: Cyclooxygenase-2 promotes hepatocellular carcinoma cell growth through Akt activation: Evidence for Akt inhibition in celecoxib-induced apoptosis. Hepatology 38: 756-768, 2003.

27. Foderà D, D'Alessandro N, Cusimano A, Poma P, Notarbartolo M, Lampiasi N, Montalto G and Cervello M: Induction of apoptosis and inhibition of cell growth in human hepatocellular carcinoma cells by COX-2 inhibitors. Ann NY Acad Sci 1028: 440-449, 2004.

28. Lampiasi N, Foderà D, D'Alessandro N, Cusimano A, Azzolina A, Tripodo C, Florena AM, Minervini MI, Notarbartolo M, Montalto G, et al: The selective cyclooxygenase-1 inhibitor SC-560 suppresses cell proliferation and induces apoptosis in human hepatocellular carcinoma cells. Int J Mol Med 17: $245-252,2006$.

29. Cusimano A, Foderà D, D'Alessandro N, Lampiasi N, Azzolina A Montalto $G$ and Cervello M: Potentiation of the antitumor effects of both selective cyclooxygenase- 1 and cyclooxygenase- 2 inhibitors in human hepatic cancer cells by inhibition of the MEK/ERK pathway. Cancer Biol Ther 6: 1461-1468, 2007.
30. Cusimano A, Foderà D, Lampiasi N, Azzolina A, Notarbartolo M Giannitrapani L, D'Alessandro N, Montalto G and Cervello M: Prostaglandin E2 receptors and COX enzymes in human hepatocellular carcinoma: Role in the regulation of cell growth. Ann NY Acad Sci 1155: 300-308, 2009.

31. Cusimano A, Azzolina A, Iovanna JL, Bachvarov D, McCubrey JA, D'Alessandro N, Montalto G and Cervello M: Novel combination of celecoxib and proteasome inhibitor MG132 provides synergistic antiproliferative and proapoptotic effects in human liver tumor cells. Cell Cycle 9: 1399-1410, 2010.

32. Cervello M, Bachvarov D, Cusimano A, Sardina F, Azzolina A, Lampiasi N, Giannitrapani L, McCubrey JA and Montalto G: COX-2-dependent and COX-2-independent mode of action of celecoxib in human liver cancer cells. OMICS 15: 383-392, 2011

33. Terzić J, Grivennikov S, Karin E and Karin M: Inflammation and colon cancer. Gastroenterology 138: 2101-2114.e5, 2010

34. Eberhart CE, Coffey RJ, Radhika A, Giardiello FM, Ferrenbach S and DuBois RN: Up-regulation of cyclooxygenase 2 gene expression in human colorectal adenomas and adenocarcinomas. Gastroenterology 107: 1183-1188, 1994

35. Gupta RA and Dubois RN: Colorectal cancer prevention and treatment by inhibition of cyclooxygenase-2. Nat Rev Cancer 1: $11-21,2001$.

36. Marnett LJ and DuBois RN: COX-2: A target for colon cancer prevention. Annu Rev Pharmacol Toxicol 42: 55-80, 2002.

37. Ogino S, Kirkner GJ, Nosho K, Irahara N, Kure S, Shima K, Hazra A, Chan AT, Dehari R, Giovannucci EL, et al: Cyclooxygenase-2 expression is an independent predictor of poor prognosis in colon cancer. Clin Cancer Res 14: 8221-8227, 2008.

38. Piazuelo E and Lanas A: NSAIDS and gastrointestinal cancer Prostaglandins Other Lipid Mediat 120: 91-96, 2015.

39. Ghanghas P, Jain S, Rana C and Sanyal SN: Chemopreventive action of non-steroidal anti-inflammatory drugs on the inflammatory pathways in colon cancer. Biomed Pharmacother 78: 239-247, 2016.

40. Wang D and DuBois RN: The role of COX-2 in intestinal inflammation and colorectal cancer. Oncogene 29: 781-788, 2010.

41. Smith AB III, Han Q, Breslin PA and Beauchamp GK: Synthesis and assignment of absolute configuration of (-)-oleocanthal: A potent, naturally occurring non-steroidal anti-inflammatory and anti-oxidant agent derived from extra virgin olive oils. Org Lett 7: 5075-5078, 2005.

42. Cusimano A, Puleio R, D'Alessandro N, Loria GR, McCubrey JA, Montalto G and Cervello M: Cytotoxic activity of the novel small molecule AKT inhibitor SC66 in hepatocellular carcinoma cells. Oncotarget 6: 1707-1722, 2015.

43. Gramignoli R, Green ML, Tahan V, Dorko K, Skvorak KJ, Marongiu F, Zao W, Venkataramanan R, Ellis ECS, Geller D, et al: Development and application of purified tissue dissociation enzyme mixtures for human hepatocyte isolation. Cell Transplant 21: 1245-1260, 2012.

44. Gramignoli R, Tahan V, Dorko K, Venkataramanan R, Fox IJ, Ellis ECS, Vosough M and Strom SC: Rapid and sensitive assessment of human hepatocyte functions. Cell Transplant 23: 1545-1556, 2014

45. Smith ML, Hawcroft G and Hull MA: The effect of non-steroidal anti-inflammatory drugs on human colorectal cancer cells: Evidence of different mechanisms of action. Eur J Cancer 36 664-674, 2000

46. Zhang Y-J, Bao Y-J, Dai Q, Yang W-Y, Cheng P, Zhu L-M, Wang B-J and Jiang F-H: mTOR signaling is involved in indomethacin and nimesulide suppression of colorectal cancer cell growth via a COX-2 independent pathway. Ann Surg Oncol 18 580-588, 2011.

47. Janssen A, Maier TJ, Schiffmann S, Coste O, Seegel M, Geisslinger G and Grösch S: Evidence of COX-2 independent induction of apoptosis and cell cycle block in human colon carcinoma cells after S- or R-ibuprofen treatment. Eur J Pharmacol 540: 24-33, 2006

48. Khan HY, Zubair H, Ullah MF, Ahmad A and Hadi SM: A prooxidant mechanism for the anticancer and chemopreventive properties of plant polyphenols. Curr Drug Targets 13: 1738-1749, 2012.

49. Lecci RM, Logrieco A and Leone A: Pro-oxidative action of polyphenols as action mechanism for their pro-apoptotic activity. Anticancer Agents Med Chem 14: 1363-1375, 2014.

50. León-González AJ, Auger C and Schini-Kerth VB: Pro-oxidant activity of polyphenols and its implication on cancer chemoprevention and chemotherapy. Biochem Pharmacol 98: 371-380, 2015. 
51. Richter C, Ghafourifar P, Schweizer M and Laffranchi R: Nitric oxide and mitochondrial $\mathrm{Ca}^{2+}$. Biochem Soc Trans 25: 914-918, 1997.

52. Trudel S, Pâquet MR and Grinstein S: Mechanism of vanadateinduced activation of tyrosine phosphorylation and of the respiratory burst in HL60 cells. Role of reduced oxygen metabolites. Biochem J 276: 611-619, 1991.

53. Bedard K and Krause K-H: The NOX family of ROS-generating NADPH oxidases: Physiology and pathophysiology. Physiol Rev 87: 245-313, 2007.

54. Scalbert A, Johnson IT and Saltmarsh M: Polyphenols: antioxidants and beyond. Am J Clin Nutr 81 (Suppl): 215S-217S, 2005.
55. Ferroni F, Maccaglia A, Pietraforte D, Turco L and Minetti M: Phenolic antioxidants and the protection of low density lipoprotein from peroxynitrite-mediated oxidations at physiologic $\mathrm{CO}_{2}$. J Agric Food Chem 52: 2866-2874, 2004.

56. Gorrini C, Harris IS and Mak TW: Modulation of oxidative stress as an anticancer strategy. Nat Rev Drug Discov 12: 931-947, 2013.

57. Trachootham D, Lu W, Ogasawara MA, Nilsa RD and Huang P: Redox regulation of cell survival. Antioxid Redox Signal 10: 1343-1374, 2008.

58. Ivanova D, Bakalova R, Lazarova D, Gadjeva V and Zhelev Z: The impact of reactive oxygen species on anticancer therapeutic strategies. Adv Clin Exp Med 22: 899-908, 2013. 